\title{
ENTRE LA FLUIDEZ Y LA FORMA: RYTHMÓS QUE RESISTEN A LOS RITMOS DE UNA ESCUELA
}

\author{
Paola Amaris-Ruidiaz ${ }^{\mathrm{i}}$ \\ Roger Miarka ${ }^{\text {ii }}$
}

\begin{abstract}
Resumen: Este artículo trae resultados de una investigación de doctorado sobre cuerpo y educación en una escuela brasileña. Específicamente opera con la idea de escuela entendida como dispositivo y espacio común, en donde se producen ritmos y rythmós, en que el primero intenta imponer una forma de vida y el segundo de escapes fluidos que generan modos de resistencia a formas de vida impuesta. Con apoyo metodológico de la cartografía, construimos una composición a partir de narrativas de dos espacios cartografiados. El primero ya institucionalizado en la estructura escolar, y un segundo, un espacio de encuentros promovido por la primera autora de este texto. Este último fue creado paralelamente al primero como forma de escape para que otras prácticas fueran posibles. Así, esperamos visibilizar otros movimientos, en que rythmós puedan resistir a prácticas que imponen ritmos.
\end{abstract}

Palabras claves: Común; Resistencia; Cuerpo; Filosofía de la Diferencia; Educación Matemática.

\section{ENTRE O FLUXO E A FORMA: RYTHMÓS QUE RESISTEM AOS RITMOS DE UMA ESCOLA}

Resumo: Este artigo traz resultados uma pesquisa de doutorado sobre corpo e educação numa escola brasileira. Especificamente opera com a ideia de escola entendida como dispositivo e como espaço comum, onde se produzem ritmos e rythmós, em que o primeiro tenta impor um modo de vida e o segundo trata de escapes fluidos que geram modos de resistência às formas de vida impostas. Com o apoio metodológico da cartografia, construímos uma composição baseada em narrativas de dois espaços cartografados. O primeiro, já institucionalizado na estrutura escolar, e um segundo, um espaço de encontros promovido pela primeira autora de este texto. Este último foi criado paralelamente ao primeiro espaço como forma de escape para que outras práticas fossem possíveis. Assim, esperamos tornar visíveis outros movimentos, nos quais rythmós possam resistir a práticas que impõem ritmos.

Palavras chaves: Comum; Resistência; Corpo; Filosofia da Diferença; Educação Matemática.

\section{La propuesta y su materialidad}

Este artículo hace parte de los resultados de una investigación de doctorado ${ }^{\mathrm{iii}}$, producida en una [Escuela $]^{\text {iv }}$ en el interior del Estado de São Paulo en Brasil, sobre el tema "cuerpo y educación". Su objetivo fue discutir la formación de profesores de matemáticas en torno de las $\operatorname{marcas}^{\mathrm{v}}$ de vida de profesores en formación continua, - tomándolas como producciones y 
productoras de subjetividades, accionándolas en cuanto a su potencia de vida - aquello que el cuerpo puede, su potencia, y, de ese modo, producir modos otros de sentir y de actuar, que potencialicen su propia práctica en la Escuela.

Metodológicamente, la investigación asumió una práctica cartográfica ${ }^{\mathrm{vi}}$ que pudiera exponer, fracturar y problematizar las relaciones de poder ${ }^{\mathrm{vii}}$ que se constituyen en la Escuela por medio de una experiencia sensible con un grupo de maestros, durante un semestre, desarrollada en dos espacios. El primero, institucional llamado "Aula de Trabalho Pedagógico Coletivo" (ATPC) ${ }^{\mathrm{viii}}$ y un segundo, llamado "Conversaciones sobre marcas de vida: espacio de creación y de potencia para profesores de matemáticas", un espacio de encuentros. Este segundo, fue creado por la investigadora, primera autora de este artículo, paralelamente al primero como una forma de escape para que otras prácticas fueran posibles.

En ese espacio paralelo se realizaron talleres a partir de las marcas de vida traídas por los profesores del grupo, con el empleo de películas, poesía, imágenes etc., para ayudar a aflorar discusiones en torno a las formas de existencia articuladas en las dimensiones éticas, políticas y estéticas de lo real. Así, se buscó, a partir de las marcas de los profesores, producir un lugar de experiencia como posibilidad de transformación y producción de otras formas de vida, en que las marcas concretizadas en el cuerpo pudieran ser visibilizadas para ser reinventadas y, con eso, producir nuevos movimientos.

En ese camino, la propuesta de este artículo es visibilizar las marcas producidas en la Escuela y concretadas en el cuerpo - considerado como epicentro de experiencia; y cómo esas marcas aumentan la potencia de actuar y pueden crear rythmós en los ritmos escolares ya existentes.

Para esa discusión fueron utilizados los conceptos de ritmo y de rythmós. Ritmo, "no tiene nada a ver con el movimiento de las ondas, pero designa la 'forma' en general, especialmente, la forma de un movimiento" (DELEUZE; GUATTARI, 1997, p.22). La noción de ritmo que operaremos tiene que ver con su expresión lingüística publicada en 1966 por Benveniste en el libro "Problèmes de linguistique générale", que relaciona etimológicamente ritmo (forma) con rythmós (fluido). Con base en esta obra, Michon (2018) toma ritmo como "forma", la disposición y la forma distintiva característica de las partes en su conjunto, como la forma del átomo, letras del alfabeto o instituciones, y lo que diferencia el ritmo de la forma, precisamente es el movimiento.

Por ese motivo, el ritmo es aquí operado como la forma que se crea en el momento en que asume lo que se mantiene de modo rítmico, y rythmós como "manera particular de fluir", o sea, disposiciones o configuraciones sin fijeza, ni medida, siempre sujeto a cambios. Así, Revista Interinstitucional Artes de Educar. Rio de Janeiro, V. 7, N. 1 - pág. 378-397 janeiroabril de 2021: "Pedagogias Vitais: Corpo, Desejo e Educação" DOI: 10.12957/riae.2021.54774 
ritmo es aquello que intenta imponer una forma y rythmós es aquello que crea otros movimientos en medio a esa forma, creando maneras propias de fluir al provocar incluso fracturas a lo que es estático y fijo.

A partir de esto, un ritmo escolar puede ser entendido como un aparato de Estado, que impone una forma en el movimiento, ni siempre percibido, que intenta regular las prácticas escolares. En consecuencia, producen discursos no fluidos, como palabras de orden. De tal manera, podemos pensar también en rythmós creados por los profesores para resistir al ritmo escolar ya existente, al crear movimientos propios no impuestos por la institución y que la atraviesan con la posibilidad de transformarla.

Para la discusión, optamos por construir una composición de fragmentos de narrativas creadas en los espacios cartografiados con discusiones sobre el ritmo escolar y los rythmós de resistencia. Con eso, esperamos generar otros movimientos, al visibilizar rythmós que resistan a prácticas que imponen determinados ritmos de vida, tiempo, pensamiento y discurso.

Presentada nuestra propuesta en torno de ritmos escolares y los rhytmós, los convidamos a una pausa para escuchar un poco de los ritmos del mundo...

\section{Ritmos de un pilón...}

Golpea, pilón, golpea, que tu sonido es el mismo desde los tiempos de los navíos negreros. ${ }^{x}$

Los golpes del pilón, un viaje sin retorno de los pueblos africanos, un sonido que retumba: agudo, resonante, - un golpe, un silencio, un golpe, un silencio. Un tiempo musical acompañado con un canto a la alegría o a la tristeza, donde las historias hacen eco, como los golpes del pilón, uno detrás de otro, recuerdan las historias, traen las memorias...

¡Golpea el pilón!

Tierra - marrón, arena, partículas. Numerosas formas, colores, olores. La música viene de la tierra, es singular, emergiendo sus propios sonidos. Los africanos cantaban las historias que acompañaban sus tareas diarias, un canto que se convirtió en música emergiendo sonidos y silencios, un pilón - "objeto evocador que lo cotidiano ofrece y desencadena el proceso de la memoria, que, persistentemente, como las reiteradas batidas del pilón" (SANTILLI, 2003, p. 208).

¡Golpea el pilón! 
Que tus sonidos vienen de la naturaleza y todo lo que produces son sonidos ancestrales, que cada golpe suene como el agua que cae a la tierra...

¡Golpea el pilón!

Que tu canto sea el lamento triste que "sempre ecoou, desde que o índio guerreiro foi pro cativeiro e de lá cantou."xi

¡Golpea el pilón!

\section{... o ritmos de una Escuela}

Golpes que traen memorias son evocados en este texto. Marcas que producen la potencia del verbo afectar, que además lleva consigo también una idea de efecto, la posibilidad de ser marcado por los afectos, que por su vez pueden producir otros efectos. Hablaremos de ritmos de la Escuela - discursos instituidos, formas de vida y silencios -, que, si escuchados de modo atento, pueden decirnos de la formación de un cierto dominio, de un intento de control. Sin embargo, no hablamos de un dominio de acciones y funciones, sino de un ethos - un conjunto de sistemas que evidencia la existencia de un común, que se presta a la participación de unos y otros, cada uno a su manera. A partir de las relaciones "entre lo que se ve y lo que se dice, entre lo que se hace y lo que se puede hacer" (RANCIÈRE, 2005, p. 59).

Maneras de hacer y decir que pueden crear lugares comunes por medio del Estado, sobre todo cuando éste instituye prácticas concretas, que intentan asegurar consistencias desde " $l a$ esfera dicha pública, hasta los modos de asociación consagrados, comunitarios, nacionales, ideológicos, partidarios" (PELBART, 2008, p. 35). Muchas veces esto se hace en nombre de la defensa a la vida, a través de mecanismos de manutención, de lo ya constituido, creando clichés producidos en cuanto a la forma de hacerlos visibles al mundo. A través de imágenes listas y pre-fabricadas, donde el pensamiento parece ser puesto en función de supuestos universales, que en su fuerza de afectación, pueden gobernar.

Con eso, identidades pueden ser producidas a partir de las configuraciones del lugar, de la asimilación o de la desaceleración del lenguaje que allí establece, a partir de los modos de hacer entorno a una verdad ${ }^{\mathrm{xii}}$, por medio de prácticas que definen su lenguaje. Pues, "hoy en día todo requiere ser re-significado políticamente: el hospital, la escuela, la vivienda, la ciudad, la cultura" (LAVAL; DARDOT, 2015, p. 600). Es por eso que por medio de esa lógica de re-significación se problematiza la Escuela, por entenderla como uno de los dispositivos ${ }^{\text {xiii }}$ socialmente más conocidos, en que el Estado la ha apropiado como forma de vida común. Y Revista Interinstitucional Artes de Educar. Rio de Janeiro, V. 7, N. 1 - pág. 378-397 janeiroabril de 2021: "Pedagogias Vitais: Corpo, Desejo e Educação" DOI: 10.12957/riae.2021.54774 
para que esa problematización no refuerce aún más los ritmos ya existentes, se requiere tomar ese común a partir de varias singularidades.

\begin{abstract}
¿Qué es ese común si no un conjunto de singularidades en variación continúa? La multitud es un concepto que intentan expresar exactamente esa relación entre lo común y lo singular. Jamás el común se sobrepone a lo singular; es la multiplicidad y la variación, es la desmedida de potencia de la multitud que el poder intenta controlar, intentan contener, regular, modular. Como se ve en ese sentido, el común no tiene nada que ver con la unidad, con la medida, con la soberanía en el sentido clásico de la palabra, y tiene mucho menos que ver con todas las figuras que pretenden representar o hablar en nombre del común, los medios de comunicación, los políticos, los imperios, por eso las resistencias pasa, hoy, por un éxodo en relación a ciertas instancias que intentan hablar en nombre del común. Tal vez la resistencia pase hoy cada vez más por una experimentación de ese común, por la constitución a partir de ese común, de nuevos espacios y nuevos tiempos. (PELBART, 2013, p. 33, traducción nuestra)
\end{abstract}

Se crean mecanismos y técnicas de poder que desean capturar en nombre de un común (a través de sus formas de acción de masas) como las instituidas en la Escuela; formas de poder sobre la vida y la potencia de la misma. Microfísica de poderes que operan de manera inminente: de arriba hacia abajo y por dentro. Engendrando una homogenización de las relaciones y produciendo seres identitarios. Prácticas que pueden definir las variaciones en el modo de sentir, sobre todo cuando se tiene "una mirada que vigila y que cada uno, la siente pesar sobre si, acabará por interiorizarlo al punto de observarse a sí mismo, cada uno ejercerá, así, esta vigilancia sobre y contra sí mismo" (FOUCAULT, 2000, p. 198).

Una relación en la cual el cuerpo se constituye como un lugar fundamental de un aprendizaje, produciendo marcas - "inscritas en el cuerpo, se encuadran y se concretizan en espacios propios donde se instala el poder sobre los cuerpos - los espacios del hospital, del asilo, la prisión o la escuela" (VILELA, 1998, p. 107). Marcas que pueden volverse naturalizadas en el momento que se concretan en el cuerpo, sobre todo cuando estas producen una variación intensa en el modo de sentir, y por consiguiente producen efectos.

Según Spinoza (1980), cada individuo podría ser definido por un grado de potencia singular y, por tanto, tiene un cierto poder de afectar y de ser afectado. Podemos cuestionar entonces ¿Cuánto de esos afectos provocan estados de dominación o cuánto de esas relaciones de poder pueden en ese amague producir resistencias?

Una experimentación inmanente de este común es urgente, nuevos espacios y tiempos pueden producir formas de vida otras, nuevos deseos hechos de multiplicidades y singularidades. Con eso destacamos que no hablamos aquí de un común como unidad 
compartida sino un común a ser creado con singularidades compartidas. Produciendo nuevos lugares sin medida, engendrando contratiempos en los espacios ya existentes para crear rythmós en los ritmos ya instituidos. En el caso de nuestra investigación, el espacio de encuentros fue la manera por la cual buscamos compartir las singularidades de los cuerpos allí presentes -los profesores- creando otro cuerpo, posibilita el flujo de rythmós en medio a los ritmos escolares.

En los siguientes fragmentos visibilizaremos las marcas que se pueden concretar en el cuerpo por medio de los ritmos escolares, y cómo esas marcas pueden crear contratiempos: un otro cuerpo, que produce rythmós, y así resistir a prácticas que imponen un ritmo: "de vida, tiempo, pensamiento y discurso" (BARTHES, 2013, p. 68).

\section{Ritmos de la Escuela}

La Escuela hace parte del Estado "y éste no se define por la existencia de jefes, se define por la perpetuación o conservación de órganos de poder" (DELEUZE; GUATTARI, 1997, p. 37). Además, posee mecanismos que intentan mantener discursos homogéneos ya constituidos. Su función primera es fijar y determinar los canales que garanticen esa manutención del Estado: "quien dispone de una violencia que no pasa por la guerra: emplea policías y carceleros de preferencia a guerreros. A través de la captura mágica, inmediata, 'agarra' y 'une', impidiendo cualquier combate" (DELEUZE; GUATTARI, 1997, p. 12).

En la Escuela existen ritmos que se hacen expresivos según las lógicas de los gobiernos y la finalidad donde está inscrita, que constituyen políticas de mantenimiento de relaciones. Esas políticas nos invitan a pensar en las relaciones de poder que se ejercen en la Escuela y en las salas de clase. Sobre todo, cuando la Escuela asume políticas que pueden enmascarar sus propias prácticas, acompañadas de sus currículos estáticos y leyes bien definidas; y esto incluso puede no dar margen a ninguna resistencia que indique la posibilidad de intentar salir de esa cerca.

\footnotetext{
Narrativa $a^{x i v}$

Espacios de encuentros:

Professor: a escola não está em ordem, cada um faz o que quer, cada um faz do jeito que quer. Para mim a Escola hoje é desorganizada, pra mim não tem mais aquele poder humanístico que tinha ali, que funcionava. Escola não é para todos. O governo quer que todos nós nos dediquemos para isso, mas não é. Então ele tem o direito de colocar todos nela, mesmo quem não está afim, e ele quer colocar o cara num mesmo nível de quem está a fim, dando valores nas mesmas coisas.
} 
La Escuela siendo un bien común, pertenece a un Aparato de Estado, y ésta puede reconfigurar los mapas sensibles de quien la habita, por medio de las relaciones de poder que allí se ejercen. Produciendo una expresión, variación e intensidades en los cuerpos, generando una asimilación del lenguaje que allí es producido.

\author{
Narrativa \\ Espacios de encuentros: \\ - Esta escola funciona? \\ - Funciona sim - responde L.- Porque os problemas que a gente tem aqui \\ não são nada comparados com as outras Escolas, e digo isso porque eu \\ também trabalho em outras escolas, e aqui podemos dar aula, embora \\ tenhamos "estudantes problema" como em qualquer Escola. \\ - Tem que ter vontade - acrescenta V. y continúa hablando. - Todo mundo \\ aqui tem que falar a mesma língua. Todos!!! Desde a direção, coordenação, \\ professor. Uma equipe.
}

Condiciones de visibilidad que pueden crear verdades, donde las prácticas de ver y hablar al mismo tiempo no son problematizadas, creando un lenguaje con sus modelos de palabra y acción, constituyendo su propio lugar, como al crear un lenguaje propio, que es entendido solo por las personas que habitan en ese espacio. Por tanto, el lenguaje producido entra "al servicio de un poder", como dice Barthes (1978) en su libro Clase, y lo más peligroso, según el mismo autor, es que lo que se crea no es ni reaccionario ni progresista, puede ser simplemente fascista, pues el fascismo no es impedir de decir, sino obligar a decir.

\begin{abstract}
Narrativa
ATPC:

Coordenadora: primeiro vem a proposta que depois é imposta. Lá, nós tivemos uma orientação e discussão do que era o currículo, do que é o currículo oficial em São Paulo, mostrando que é um material que vem com o caderno do professor e do aluno. Uma novidade é: como o currículo se dá no aprendizado? E daí nós, coordenadores, seremos gestores pedagógicos do currículo, a nova função é ir à sala de aula verificar se o currículo está sendo aplicando ou não, e se vocês não estiverem aplicando verificar a razão disso, devo DO-CU-MEN-TAR tudo!
\end{abstract}

Esas configuraciones de lenguajes y prácticas son las que nos hacen pensar en las relaciones que se producen, sobre todo cuando "el cuerpo se encuentra ahí en posición de instrumento o de intermediarios: cualquier intervención sobre él, por el trabajo obligatorio, puede privar el individuo de su libertad considerada al mismo tiempo como un derecho o como un bien" (FOUCAULT, 1996, p. 76). Por eso, cuando el común es instituido y el Estado se apropia de éste, se generan prácticas que necesitan ser cumplidas, para mantener ese común como un bien, como una propiedad, bajo lógicas y dinámicas que el propio Estado genera. Éstas 
prácticas pueden concretizarse en el cuerpo, puesto que el común proveniene de políticas de Estado, y el cuerpo también es un territorio concreto.

Un cuerpo no es solo un objeto epistémico, o una simples superficie de inscripción de las marcas significantes de la historia - un territorio concreto de visibilidades absolutas. Él posee un peso ontológico porque es lugar necesario de sentido: el cuerpo simboliza porque es evidenciado por el símbolo y porque en él, el símbolo se hace cuerpo (VILELA, 1998, p. 179, traducción nuestra).

En Vigilar y Castigar, Foucault (1996) presenta un estudio donde el cuerpo es el punto focal de poder en medio a una microfísica del mismo. En un capítulo llamado "cuerpos dóciles", nos alerta sobre el descubrimiento del cuerpo como un objeto de poder. Es dócil un cuerpo que puede transformarse para ser utilizado. Lo que se desea, por lo tanto, es que los cuerpos dóciles sean cuerpos útiles, a través de técnicas disciplinarias que se ocupan esencialmente de la organización del espacio, el tiempo y las capacidades.

Según Foucault (1996), la Escuela se constituye como una estructura disciplinar, ya que cumple con características de ubicaciones funcionales - "cada individuo en su lugar; y en cada lugar, un individuo" (1996, p. 123). Los "cuadros vivos" son al mismo tiempo una técnica de poder y un proceso de conocimiento cuya intención es dominar la diversidad imponiéndole un orden.

La escuela se convierte en una especie de aparato de examen ininterrumpido que acompaña a toda su obligación la operación de la enseñanza. [...] una comparación perpetua de cada uno con todos, que permite tanto la medición como la sanción. [...] El examen permite al profesor, mientras transmite su conocimiento, elevar un campo de conocimiento sobre sus alumnos. [...] el examen es en la escuela un verdadero y constante intercambio de conocimiento: garantiza el paso del conocimiento del maestro al estudiante, pero elimina del estudiante un conocimiento destinado y reservado para el maestro. La escuela se convierte en el lugar de elaboración de la pedagogía. [...] la era de la escuela: el examen marcó el comienzo de una pedagogía que funciona como ciencia. [...] El examen supone un mecanismo que vincula un cierto tipo de formación de conocimiento a una determinada forma de ejercicio del poder (FOUCAULT, 1996, p. 155, traducción nuestra).

De esa manera la Escuela crea una determinada forma por medio de técnicas de poder y procesos de saber, determinados por aparatos de examen que los regulan y, a partir de eso, se generan ritmos escolares que intentan producir cuerpos organizados, imponiendo su forma de modo a docilizarlos. Esos ritmos impuestos son visibles en la Escuela por medio de algunos mecanismos de control, por ejemplo: currículos, planillas, reuniones, ATPC; o hasta de aquellos 
indicadores de tiempo, como el timbre que anuncia el movimiento que se aproxima. De esa manera, el tiempo hace parte también de la capitalización de la producción, pues éste también divide, ordena, fija y dispone.

Foucault usa el concepto de gubernamentalidad para describir las "instituciones, los procedimientos, análisis y reflexiones, los cálculos y las tácticas" (FOUCAULT, 2008, p. 143). Procesos de disciplinarización y normalización de los individuos que se realizan a través de meticulosos procesos de vigilancia y control sobre el cuerpo. Esos procesos son los que generan esos ritmos escolares, sobre todo cuando estos afectan al cuerpo, pues éste "es un elemento fundamental de los juegos de poder y verdad, una vez articulados entre el saber y el poder, se define una tecnología política a través de la cual el cuerpo se torna un efecto-objeto" (VILELA, 2011, p. 14).

\begin{abstract}
Ahora, a medida que las relaciones de saber y poder, así como los discursos tomados como verdades incuestionables, circulan en la sociedad, la escuela también se ve atravesada por estas cuestiones. Más que eso, la escuela es un lugar estratégico para aprender, no solo el conocimiento socialmente aceptado sino como lo "mejor que la sociedad ya ha producido en la historia de la humanidad". En la escuela opera un dispositivo pedagógico que actúa como una técnica o herramienta para determinar qué es verdadero y qué es falso, abordando valores, conocimientos y comportamientos. (SILVA, 2019, p. 384, traducción nuestra)
\end{abstract}

La Escuela forma parte de una lógica de gobierno regida por el neoliberalismo ${ }^{\mathrm{xv}}$, por lo que podría llamarse también una "Escuela Neoliberal”’xi , que puede traducirse en seguir ciertas reglas que valoran el espíritu emprendedor, estimulan la competitividad y responsabilizan a los individuos. Además, “la selección de materias válidas y legítimas para ser enseñadas también implica la selección de valores, comportamientos y moralidades, que están integrados en este conocimiento" (SILVA, 2019, p. 384). Así, la lógica neoliberal puede entenderse dentro de las relaciones de poder y el conocimiento movilizado por los Estados como tácticas eficientes de gobierno, y aquellos ritmos escolares impuestos hacen parte de esas tácticas, pues, garantizan su manutención para mantener su propia forma.

\footnotetext{
Narrativa

Espacios de encuentros:

- Eu fico agoniada com esta apostila ${ }^{\mathrm{xvi}}$. Está terminando o sexto ano, vai ser o segundo volume. Você pensa que vamos acabá-la? Eu só vou dar equações e pronto. Por exemplo, o livro didático há 15 anos é a mesma coisa, só mudam os desenhos.

P. tenía una duda y tuvo que preguntar algo para saber un poco de ellas y su carga académica

- Vocês trabalham em outras escolas?
} 
- Em mais três escolas - responde M.

- Em mais duas - responde L.

- Só aqui nessa escola com seis turmas - responde $V$.

P. continúa con otra pregunta.

- Vocês têm tempo para preparar suas aulas?

- Tempo? - responde M. sonriendo. - É difícil, nossa situação é difícil. Às vezes dá outras vezes não, mas sim, somos responsáveis, mas eu gostaria de fazer coisas diferentes, quero que eles gostem, mas só temos seis horas de aula, deveriam ser 10, o tempo não dá pra tanto conteúdo - M. cierra su argumento diciendo. - Às vezes o tempo foge.

Por otro lado, V. le pide desesperadamente ayuda a P.

- Nós precisamos de ajuda, não sabemos o que fazer para que eles tenham interesse!!!

\title{
Rythmós
}

Según Roland Barthes en Como vivir juntos (2013), rythmós se le vincula con rhein (fluido), que puede ser comprendido como movimiento regular de las ondas. En esa perspectiva, rythmós no significa "ritmo", no se aplica al movimiento regular de las aguas, pues su sentido es de forma distintiva, figura proporcionada y disposición. Rythmós son elementos fluidos, improvisados y modificables. Sin embargo, esos rythmós también pueden ser bloqueados, por ejemplo, por la familia como una forma represiva, o en los conventos, o en la Escuela, porque son estructurados según una arquitectura del poder. Así como también el profesor cuando asume un ritmo, que representa el ejercicio de poder más visible por medio del currículo y sus tiempos.

\begin{abstract}
Narrativa
ATPC:

Coordinadora: - Os lineamentos buscam uma cultura pública para todo o país. Nosso lineamento é FE-DE-RAL. Por isso a gente tem que seguir. Não esqueçam também que temos que fazer uma avaliação, observar o aluno de maneira global. O aluno aprende a aprender, mas têm coisas que eles têm que memorizar, Ensino Médio tem que ter uma progressão continuada, mas por isso virou a bagunça que virou. Ninguém sabe para que serve o Ensino Médio? É transformar numa coisa pronta. Ensino Médio é para preparar para o vestibular ou para prepará-los para o mundo de trabalho? Ninguém sabe para que funciona o Ensino Médio. Ensino Médio não supre do jeito que eles falam. Qual é a nossa maior congruência? - o currículo oficial respondiendo Ella a su pregunta.-Esse é o documento preto, é a base de tudo, o caderno do aluno e do professor é recorte do currículo, não contém o currículo inteiro, porque nem caberia, ele contempla o recorte, e a prova do SARESP também é o recorte do currículo, por isso que não vou nem fazer rodeio, TEM QUE usar apostila na sala de aula.
\end{abstract}


La Escuela ha configurado su lugar, volviéndose una ordenación de $\operatorname{signos}^{\mathrm{xviii}}$, donde sus enunciados son los que determinan la función de lo que allí se ejerce, creando también un lenguaje a partir de las formas y los modos de hacer, en torno a una política que se rige, en nuestro caso, un Aparato de Estado que ejerce su función. Definiendo las palabras y las formas de acción, trazando y creando mapas sensibles entre lo que se dice y lo que se ve, produciendo así los modos de ser, sentir, hacer y decir. O sea, producen ritmos a ser mantenidos.

Ahora ¿Cómo producir deseos en el pensamiento, en el discurso y en la acción? “ ¿Cómo el deseo puede y debe desdoblar sus fuerzas en la esfera de lo político e intensificarse en el proceso de reversión de la orden establecida?" (FOUCAULT, 2004, p. 13).

Asumir que se pueden producir ryhtmós en los ritmos escolares implica que el orden actual de las cosas, junto con sus formas de hacer y de decir, no lo puede ser todo. Para eso se necesita salir del lugar de confort en donde esas obligaciones rítmicas no se vuelvan creencias establecidas, y por tanto objetos de verdad. El sistema no aguanta ser el mismo por mucho tiempo. Es en esas tensiones en donde podemos producir gestos que asuman el lugar de las posibles ilusiones de la palabra y el papel, y devolverle a la utopia "su carácter de 'irrealidad" de montaje de palabras e imágenes, que le es proprio para reconfigurar el territorio, de lo pensable y de lo posible" (RANCIÈRE, 2005, p. 62).

Con todo esto ¿Cómo producir rythmós en los ritmos escolares existentes?

Junto a esa pregunta y de acuerdo con Barthes (2013) discutimos lo siguiente: es igual pensar la violencia sufrida por el pensamiento, como una formación del pensamiento sobre la acción de las fuerzas selectivas, un adiestramiento que pone en juego el inconsciente del pensador, es decir, la paideía de los griegos, no entendida como un método sino que un programa de formación en constante movimiento de renovación. Para esto, se hace necesario volver a la idea nietzschiana de fuerza como engendramiento de una diferencia: podemos ser amenos, civilizados mismos y colocarnos en la paideía.

Estos elementos nos ayudan a pensar en la posibilidad de asumir la educación como una práctica de afectos, en que la potencia que se manifiesta como el fenómeno de una fuerza, pueda ser afectada por otra. El ser afectado no se traduce en un instante pasivo de determinada fuerza. Es más, se revela ante la sensibilidad al poder de la otra fuerza. Esto se expresa sobre una descarga de fuerza sobre otra, una voluntad que puede ser interpretada sobre la forma de un querer - "son efectos del propio querer y esta creencia vuelve más fuerte el sentimiento de poder que él siente" (NIETZSCHE, 2001b, p. 27).

Nietzsche interpreta y traduce el juego de sentimientos, pensamientos, deseos, pasiones, inclinaciones y así la propia vida como un juego de relaciones e impulsos. El concepto de Revista Interinstitucional Artes de Educar. Rio de Janeiro, V. 7, N. 1 - pág. 378-397 janeiroabril de 2021: "Pedagogias Vitais: Corpo, Desejo e Educação" DOI: 10.12957/riae.2021.54774 


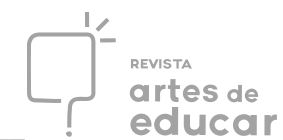

voluntad está acompañado por potencia, pero esta voluntad no es la causa de la potencia. A partir del momento en que se la comprende como una pluralidad de impulsos, esta puede generar diferentes rythmós, que pueden potenciar esa voluntad, insiriendo fuerzas en el sentido de que todo acontecimiento es explicado en términos de voluntad de poder, ya que no se "afronta al mundo de los objetos sino el mundo de las fuerzas y las intesidades" (VILELA, 2009, p. 23).

\begin{abstract}
Narrativa
Espacios de encuentros:

Professora: Eu sinto por algumas situações na sala de aula. Eu fiz várias carinhas. Na primeira, eu quis mostrar como fico chocada, assustada pelas posturas de alguns alunos, assustada do jeito que eles podem confrontar a gente com falta de respeito. Na segunda eu coloquei carinha de apaixonada. Por quê? Porque tem dias... Nossa!! Eu saio apaixonada, com paixão do que eu faço, porque eu gosto do que eu faço, com todos os contratempos, mas eu amo...então, tenho paixão mesmo pelo que eu faço...Por outro lado, eu fico triste: triste pela falta de cultura, pela falta de valor, triste porque às vezes parecer que tanto faz você estar ali, triste... Enfim, são três carinhas que me representam, na minha sala, eu não consigo entender.
\end{abstract}

Spinoza afirma, en su Ética (1980), que un cuerpo es afectado de muchas maneras, pero hay dos afectos fundamentales: la alegría, "el afecto que aumenta nuestra potencia de actuar y la tristeza, el afecto que la disminuye" (SPINOZA, 1980, p. 85). La potencia para actuar aumenta o disminuye en virtud de las ideas y los buenos encuentros que se tienen. Esos afectos son los que mueven nuestra voluntad y son los que pueden generar otros movimientos.

Asumir que se pueden producir rythmós en los espacios escolares es pensar en un otro movimiento, en que las notas musicales no sean siempre las mismas y no reflejen un ritmo escolar armonizado, como el propio sistema quiere mostrarnos. Del mismo modo, si se crean nuevas estrategias de poder, éstas pueden fracturar las líneas de poder naturalizadas en la Escuela, expresadas en las "maneras de hacer". Al intentar crear espacios que aumenten las capacidades de ser afectados se puede producir incluso un aprender que no sea solamente enseñar-aprender, o sea, causa-efecto, sino, crear acontecimientos singulares en el pensamiento.

\title{
Narrativa
}

Espacios de encuentros:

- Eu tive um professor, que eu não lembro nada do que ele passou. Não tinha alma. - Todas de nuevo rieron con una gran fuerza del comentario de $V$.

En ese momento P. le pregunta:

- Mas essa alma era no sentido de que ele não sabia passar a matéria?

- Eu tenho muito respeito por esse professor - le responde. - Eu aprendi, mas o jeito como ele dava a matéria - en ese momento ella suspira fuertemente.-Os alunos às vezes nem existiam para ele. Mas, eu lembro uma 
vez algo que nos ensinou, não esqueço, era até matriz, fez tudo de um jeito tão fácil e sensivel que eu aprendi.

- Pois é - comenta S. - Realmente o que você aprende, não esquece. É o que eu falo para eles. Se você esqueceu é que você não aprendeu, eu falo isso para eles. Ahhh é que não lembrooo. Então você não aprendeu.

- Pensem nesse professor maravilhoso - comenta L. - Que você prestou atenção, você aprende.

En ese camino, y si nos colocamos en la paideía, como anuncia Barthes (2013), podríamos producir actos estéticos que envuelvan configuraciones de otras experiencias, que puedan dar origen a nuevas formas de sentir, nuevas producciones de subjetividades como: un golpe, un silencio, un golpe, un silencio. Esto hace parte del ritmo musical, en que un silencio es una señal que representa gráficamente la duración de cierta pausa en la música. Pausas y silencios hacen parte de la clase, como el tiempo que el estudiante lleva para aprender.

Siempre hay alguien que no entiende en el momento. Es lo que llamamos de efecto retardado. También es como en la música. En el momento, usted no entiende un movimiento, pero tres minutos después, aquello se vuelve claro porque algo aconteció en ese instante. Una clase puede tener efecto retardado. Podemos no entender nada en el momento y diez minutos después, todo se esclarece. Hay un efecto retroactivo. Si El ya interrumpió...Es por eso que las interrupciones y me preguntas me parecen bobas. Usted pregunta porque no entiende, pero basta esperar. (DELEUZE; PARNET, 1987, p. 26)

Al colocarnos en la paideía también podemos redefinir la relación entre profesor y estudiante, creando espacios para que los buenos encuentros aumenten la capacidad de afectar y ser afectados.

\begin{abstract}
Narrativa
Espacios de encuentros:

Não é que a escola não tenha saída, né? Mas você luta contra uma coisa que não vai ganhar. A gente não tem apoio - dice $K$.

- Não tem não - afirma también $V$.

- O ser humano pode ser gentil - continúa B. hablando. -, mas se a gente tivesse mais amparo na Escola, poderia ser até diferente. Você entra na sala de aula, para de falar, porque sua turma não presta atenção, de repente não dá retorno, daí entra a questão, como é ser gentil numa sala que não é gentil com você? O ser humano, ele é gentil, mas ele acaba sendo egoísta: vou dar atenção, se você me der atenção. É diferente a gente estar num supermercado, fora do convivio que a gente tem. A gente convive mais com alunos que com os pais. Por exemplo, se você conhece aquele aluno e ele foi mal educado com você, a gente vai retribuir ao aluno de uma maneira diferente.
\end{abstract}

Al colocarnos en la paideía es sentir la Escuela como una multitud producida por singularidades, no como un espacio abstracto individual producido por sujetos. Jamás el común 


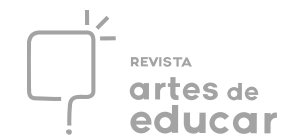

se sobrepone a lo singular, como cuando se quiere sobreponer la individualidad encima de todo colectivo común, así ¿Qué pueden rythmós en los ritmos ya existentes de la Escuela?

\title{
Resistir a ritmos
}

\begin{abstract}
Narrativa
Espacios de encuentros:

- Escutei que aqui o currículo dá certo? É verdade isso? - le preguntó P.

- O currículo até que funciona - dice K. y continúa hablando. -Olha, você tem uma lista de coisas, por exemplo: Matemática, você tem que dar isto, isto, isto, isto. Currículo. Daí, cada bimestre você tem que atingir seu objetivo. Agora, o que eu não gosto do currículo é o que eles fazem, é para isto: apostila, apostila, apostila e data. Eu não deveria estar obrigado a usar apostila, inclusive a apostila a maioria de estudantes ficam com isso só, às vezes nem consultam mais livros, ficam contentes por resolver a figura tal com a opção $a, b, c, d$.
\end{abstract}

Cuando las prácticas de poder intentan homogenizar los espacios, y éstas se concretan en el cuerpo, crean un cuerpo-marcado, así también los rythmós pueden ser capturados para que se vuelvan parte de los ritmos ya existentes. En ese camino problematizamos ¿Qué pueden las marcas que se concretizan en el cuerpo y qué pueden los espacios de encuentro?

Resistir es existir y este movimiento hace parte de la potencia de afectar y ser afectado, como cuando el profesor dice: "Yo no debería estar obligado a..." Allí se están creando gestos que escapan a los discursos dominantes, re-significándose. Otro lenguaje es producido, provocando una heterorritmia ${ }^{x i x}$, y esto acontece en agrupamientos, cuando varios cuerpos intentan vivir juntos, y donde cada uno lucha por operar con su propio rythmós. Un movimiento otro es producido por una ética singular y no por el ritmo de la obligación. Rythmós que desafían ritmos impuestos.

Es por eso que donde se engendran practicas de poder se pueden crear otros modos de resistencias. "Así mismo, [o mejor, por eso mismo] ésta [la resistencia] nunca se encuentra en posición de exterioridad en relación al poder... [la resistencia] por definición, no puede existir a no ser en el campo estratégicos de las relaciones de poder" (FOUCAULT, 2006, p. 91). Siendo así que para resistir es necesario que la resistencia sea tan inventiva como el poder, "tan móvil, tan productiva como el mismo" (FOUCAULT, 1996, p. 267).

\section{Narrativa}

Espacios de encuentros:

Professor: por exemplo: tenho três alunos com formações diferentes, com dificuldades diferentes, eu tenho que criar artimanhas, criar situações que 
envolvam os alunos. Assimé que eu consigo fazer alguma coisa, tem que fazer esse papel de uma maneira crítica, isso a gente aprende, na experiência nossa, e nossos alunos...

A gente aprende pelos resultados deles, pela demonstração de carinho do último dia, como hoje, eu tenho sorte cara, por exemplo, por mais divergente que seja a gente aprende com eles, então, o papel da gente é criar artimanhas, só... Hoje é um dia especial, e estou emocionado por ser o último dia de alguns dos estudantes, assim que me desculpem pela emoção. Uma coisa a mais. Eu acho que eles têm potencial, mais do que a gente pode dar... tudo bem! A gente tem os parabéns, mas eu acho que nosso aluno tem um potencial maior.

En el momento que cada persona puede ser definida por su grado de potencia singular, ésta solo es producida junto al otro. Son los encuentros entre cuerpos que dan las posibilidades de aumentar los afectos, y, quizás así, puedan provocar salir del control del dispositivo en que se está inmerso. "No sabemos cuánto puede un cuerpo hasta que este sea afectado, siempre será cuestión de experimentación" (PELBART, 2008, p. 4).

En ese camino los espacios de encuentro creados en la [Escuela] ayudaron a problematizar ¿Qué puede un cuerpo? pues "los individuos construyen mundos desde la base de los universos posibles, un proceso estético que crea lo nuevo, que disloca los problemas, disloca los universos de percepciones que no comprenden los objetos y no funcionan con las mismas reglas, crean posibilidades inéditas" ${ }^{\mathrm{xx}}$. Posibilidades creadas que contribuyeron a que los maestros pensaran en su propia práctica, y sobre todo a abrir posibilidades otras por medio de un cuidado de si:

¿Cómo el profesor puede lidiar con las subjetivaciones (poderes) instituidas en la escuela? Un camino para esta respuesta es tratado por Foucault (2010) que muestra, a través de las practicas y de los ejercicios del cuidado de si y de la autonomía en la Grecia, que no hay otra forma de resistencia al poder si no en la relación de si para consigo. O sea, Foucault nos muestra que hay un poder que el sujeto puede manipular: el poder sobre él mismo. (DE SOUZA; TUCHAPESK, 2015, p. 1314, traducción nuestra)

Espacios de encuentro pensados como posibilidad de crear afectos ¿Qué tanto nuestras acciones contribuyen con esto? Existir es variar nuestra potencia de actuar. Por eso la Escuela debe ser pensada como potencializadora de alegrías, los afectos que, según Spinoza (1980), pueden aumentar esa potencia de actuar. Los malos encuentros, que están a merced de la cotidianidad escolar, no pueden ser solo la base de la producción de afectos, pues solo generan resentimientos y disminuyen esa potencia. Los afectos no son un problema, como dice Spinoza, ellos existen y son inevitables. No son buenos ni malos. Son sencillamente necesarios en los encuentros entre cuerpos y para las ideas que estos crean. 
Con ese panorama estamos en una crisis del común. Lo que antes parecía garantizar un contorno común, asegurando su subsistencia y lazos, perdieron potencia. Esto posibilita pensar en que algo se ha agotado, provocando la posibilidad de desgarramientos, es allí donde se puede crear una frontera entre lo que se desea y lo que se recusa. Ese entre es lo que puede potenciar un cuerpo que resiste - " un acto que en su actualidad arrastra consigo la matriz de la creación: la potencia política y estética de la creación de sí y de la creación de nuevas formas posibles de poder, de nuevas relaciones estratégicas de poder" (VILELA, 2013, p. 104).

Cuando hablamos de la Escuela como un lugar común, debemos evitar pensar ese común como un todo. Sí, es un bien del Estado porque hace parte del Aparato de Estado, pero antes que más nada es un lugar político, por tanto, debe ser pensado y dislocado, puesto que es un lugar en variación continua, entre lo común y lo singular. Debemos estar atentos a las prácticas de poder que intentan controlarlo, con disposición para crear espacios de salidas o de invención.

“El común no tiene nada que ver con la unidad, con la medida, con la soberanía en el sentido clásico de la palabra, y tiene mucho menos que ver con todas las figuras que pretenden representar o hablar en nombre del común" (PELBART, 2013, p. 24). Talvez la resistencia pase hoy cada vez más por una experimentación de ese común. La Escuela, por ser un bien que hace parte del Estado, puede y debe ser un espacio de experimentación, donde los ritmos impuestos no sean los que exclusivamente caractericen ese común.

\section{Golpea el pilón}

Si asumimos la Escuela como territorio existencial ${ }^{\mathrm{xxi}}$, podríamos hablar de la vida y los procesos que en ella se pueden reinventar y crear. La Escuela puede ser un espacio de creación si es asumida como un lugar de práctica de afectos, y éstos puedan aumentar la potencia de actuar de quien la habita. Los espacios de encuentros posibilitan aberturas dentro del propio Aparato de Estado, generando ciertos encuentros que pueden extrapolar repentinamente el marco de referencia habitual, haciendo sentir la fuerza de aquello que no se manifiesta inmediatamente, sobre todo, creando percepciones y sensaciones extrañas, es decir, nuevas.

Una experimentación inmanente de ese común es urgente. Ocupar y producir espacios que puedan crear rythtmós en medio a los ritmos ya existentes sería una forma de ruptura, y si se visibiliza que algo se está agotando, podemos desatar aquello que nos conecta al mundo, y así otras formas de vida pueden crearse. Producir multiplicidad en los lugares ya instituidos es Revista Interinstitucional Artes de Educar. Rio de Janeiro, V. 7, N. 1 - pág. 378-397 janeiroabril de 2021: "Pedagogias Vitais: Corpo, Desejo e Educação" DOI: 10.12957/riae.2021.54774 
una forma de resistencia, así ¿Qué nuevos encuentros creamos cada día como posibilidades de producir afectos que potencialicen otras formas de existencia?

...Y cuando el pilón suena, hace eco y resonancia, como este texto y sus letras retumbantes ¿Qué podemos sentir?

¡Golpea el pilón!

Que tu sonido agudo y resonante, sea el disparador de memoria, para que ésta reverbere en el pasado e interrogue el presente.

¡Golpea el pilón!

Una historia contada al toque del pilón - golpes, silencios y rythmos son producidos mientras un ritmo de golpe suena.

\section{REFERENCIAS}

AMARIS-RUIDIAZ, P; MIARKA, R. Escrita-Corpo-Experiência e Literatura: que pode o escrever (na pesquisa) [em educação matemática]?. Alexandria: Revista de Educação em Ciência e Tecnologia, v. 11, n. 3, p. 13-31, set. 2018.

BARTHES, R. Como viver junto: simulações romanescas de alguns espaços cotidianos: cursos e seminários no Collège de France, 1976-1977. São Paulo:Editora WMF, 2013.

BARTHES, R. Aula. Tradução de Leyla Perrone-Moisés. São Paulo: Editora Cultrix, 1978.

DELEUZE, G. ¿Qué es un dispositivo? Barcelona: Gedisa, 1990.

DELEUZE, G. Diferença e repetição. Tradução de Luiz Orlandi e Roberto Machado. Rio de Janeiro: Relógio D’ Agua Editores, 2000.

DELEUZE, G; GUATTARI, F. Mil Platôs: capitalismo e esquizofrenia. Tradução Peter Pál Pelbart ; Janice Caiafa. V. 5. Rio de Janeiro: Editora 34, 1997.

DELEUZE, G; PARNET, C. L'abécédaire de Gilles Deleuze: Claire Parnet. Paris: Montparnasse Liberation, 1987.

DE SOUZA, A; TUCHAPESK, M. Do Conceito à Prática da Autonomia do Professor de Matemática. Bolema, Rio Claro (SP), v. 29, n. 53, p.1309-132, 2015.

FOUCAULT, M. Introdução à vida não fascista. Prefácio. G. Deleuze, \& F. Guattari, AntiEdipus: capitalism and schizophrenia, 2004.

FOUCAULT, M. História da Sexualidade 1: a vontade de saber. Tradução de Maria Thereza da Costa Albuquerque e J. A. Guilhon Albuquerque. 17. ed. Rio de Janeiro: Edições Graal, 2006. 
FOUCAULT, M. Vigiar e Punir. 13. ed. Petrópolis: Vozes, 1996.

FOUCAULT, M. Microfísica do poder. Rio de Janeiro: Graal, 1979.

FOUCAULT, M. Ditos e escritos v. 2. Arqueologia das ciências e história dos sistemas de pensamento. MOTTA, Manoel Barros da (Org.). Rio de Janeiro: Forense Universitária, 2000.

FOUCAULT, M. Hermenéutica del sujeto. Madrid: Ediciones de la piquera, 1994.

LAVAL, C; DARDOT, P. Común. Ensayo sobre la revolución en el siglo XXI. Barcelona: Editorial Gedisa, 2015.

LAVAL, C. A escola não é uma empresa: o neoliberalismo em ataque ao ensino público. São Paulo: Boitempo, 2019.

MICHON, P. Rythme et théorie du langage: une introduction. Rhuthmos, 24 avril, 2018. Disponivel em: http://rhuthmos.eu/spip.php?article781.

NIETZSCHE, F. A Gaia Ciência. Tradução P.C Souza. São Paulo: Companhia das Letras, 2001a.

NIETZSCHE, F. Além do bem e do mal ou prelúdio de uma filosofia do futuro. São Paulo: Hemus S.A, $2001 b$.

PASSOS, E; KASTRUP, V. Sobre a validação da pesquisa cartográfica: acesso à experiência, consistência e produção de efeitos. Revista Fractal, v. 25, n.2, p. 391-414, 2013.

PASSOS, E; BARROS, R. Cartografar é acompanhar processos. En: Pistas do método da cartografia: pesquisa intervenção e produção de subjetividade. Editado por: Eduardo Barros, Virginia Kastrup. Porto Alegre: Sulina, 2009.

PELBART, P. Elementos para uma cartografia da grupalidade. Próximo ato: questões da teatralidade contemporânea. São Paulo: Itaú Cultural, 2008.

PELBART, P. Políticas da vida, produção do comum e a vida em jogo. Saúde Soc. São Paulo v.24, n. 1, p.19-26, 2013.

RANCIÈRE, J. Estética e política: a partilha do sensível. São Paulo: Editora 34, 2005.

ROLNIK, S. Pensamento, corpo e devir. Uma perspectiva ético/estético/política no trabalho acadêmico. In: Cadernos de Subjetividade. PUC/SP. SP, v.1 n. 2, p. 241-251, Set./Fev. 1993.

SANTILLI, M. Paralelas e tangentes: entre literaturas de língua portuguesa (No. 4). Arte \& Ciência, 2003.

SILVA, M. A. A Política Cultural dos Livros Didáticos de Matemática: um guia para transformar estudantes em cidadãos neoliberais. Linhas Críticas, v. 25, pp. 381-398, 2019. Disponível em: <http://periodicos.unb.br/index.php/linhascriticas/article/view/21853>. 
SPINOZA, B. ÉTICA. Demostrada según el orden geométrico. Madrid: Editora Nacional, 1980.

VILELA, E. Do corpo Equívoco. Braga/Coimbra: Angelus Novus, 1998.

VILELA, E. Bajo los vestigios de un cuerpo: cultura, discurso y acontecimiento. En: Calle 14: revista de investigación en el campo del arte, vol. 3, no 3. 2009.

VILELA, E. Michel Foucault, uma filosofia analítica do poder: marcas, sinais e traços do silencio. En: Foucault, Deleuze \& Educação. Editado por Sonia Clareto. Juiz de Fora: Editora UFJF, 2013.

\footnotetext{
i Post-doctoranda (PNPD) en la "Universidade Federal de Mato Grosso do Sul". Doctora en Educación Matemática por la "Universidade Estadual Paulista" (UNESP), campus Rio Claro, São Paulo. Brasil. E-mail: paolaamaris@gmail. ORCID iD https://orcid.org/0000-0001-6683-5359.

ii Livre Docente y doctor en Educación Matemática por la "Universidade Estadual Paulista" (UNESP), campus Rio Claro. Profesor en la misma institución. Dirección para correspondencia: Avenida 24A, 1515, Bela Vista, CEP: 13506-900, Rio Claro, SP, Brasil. E-mail: roger.miarka@unesp.br. ORCID iD https://orcid.org/00000002-0633-8446.
}

${ }^{i i i}$ Tesis titulada Encontros e fluxos numa escola: educadora matemática em potência de criação, fratura e resistência. Puede ser descargada en el siguiente link: http://hdl.handle.net/11449/155962. Investigación financiada por la CAPES.

iv En este artículo se trabajará con tres grafías, con diferencias sutiles: la primera, Escuela, dice de un dispositivo foucaultiano; la segunda, [Escuela], en lugar del nombre real de la escuela habitada por la investigadora, para cualquier tipo de representacíon, donde se espera aflore sus singularidades por medio de una investigaciónintevensión; y la tercera, la forma ordinaria escuela, utilizada en los fragmentos transcriptos.

"En este texto, tomamos "marcas", segundo Rolnik (1993, p.241), como un tipo de memoria de lo invisible producida por afectaciones y cargada en el cuerpo.

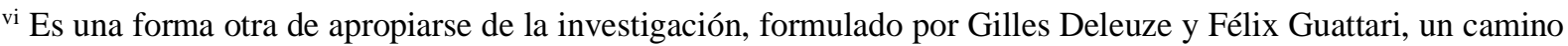
que nos ayuda en el estudio de las subjetividades dadas algunas de sus características. Segundo Passos y Barros (2009, p.76), “[...] no es un método lineal y listo [...] Es un procedimiento ad hoc, a ser construido caso a caso [...] Es procesual y se va haciendo en el acompañamiento de los movimientos de las subjetividades y del territorio".

vii Según Vilela (1998, p. 159), esas relaciones son "entendidas como un fenómeno social que se manifiesta de la forma más simples, desde que cualquier sujeto se esfuerza por influenciar el comportamiento de un otro - se origina en los movimientos de acción de los individuos. Lo que significa que, por la acción, el individuo puede impedir que las relaciones de poder se perpetúen en estados de dominación."

viii Optamos por utilizar el nombre "Aula de Trabalho Pedagógico Coletivo (ATPC)" en portugués, una vez que ese espacio es propio de la estructura escolar pública brasileña. Una posible traducción al español es "Clase de Trabajo Pedagógico Colectivo". Fue instituida en las escuelas públicas por el Gobierno del Estado de São Paulo a través de CENP n ${ }^{\circ} 1 / 96$, ley complementar n ${ }^{\circ} 836 / 1997$, articulo13, para que los profesores de todas las áreas de una escuela se reuniran semanalmente junto a la parte administrativa de la Escuela para discutir cuestiones pedagógicas colectivamente.

ix BENVENISTE, Émile. Problèmes de linguistique générale. Paris: G.allimard, 1966.

$x$ (SANTILLI, 2003, p. 208).

${ }^{x i}$ Canto das três raças. Intérprete: Clara Nunes. Compositor: Mauro Duarte/Paulo César Pinheiro. 1976. Cd. faixa 1 (4 min). 
xii Deseamos la verdad, pero ¿por qué alejar lo no verdadero o la incerteza y hasta la ignorancia? ¿Fue el problema de validar lo verdadero que se coloco frente a nosotros o fuimos nosotros que lo buscamos? (NIETZSCHE 2001a, p.10).

xiii Un conjunto heterogéneo que engloba discursos, instituciones, organizaciones arquitectónicas, decisiones reglamentares, leyes, medidas administrativas, enunciados científicos, preposiciones filosóficas, morales y filantrópicas. En suma, lo dicho o no dicho son los elementos del dispositivo. El dispositivo es la red que se puede establecer entre estos elementos (FOUCAULT, 1979, p. 244).

${ }^{\text {xiv }}$ Los fragmentos de narrativas creados en los espacios de encuentros de la investigación aquí presentados están en una forma mezclada en español y portugués. La opción por esa política narrativa busca mantener ciertas líneas de intensidad de los discursos proferidos en un espacio con participantes de diferentes países. Una discusión más detallada sobre eso puede ser encontrada en (Autores, 2018).

${ }^{\mathrm{xv}}$ Neoliberalismo es una política económica fundamentada, como todo principio económico, no solo en decisiones políticas sobre cómo el mercado debe funcionar, sino también por medio de características que regulan comportamientos y establecen metas para la sociedad, según determinados valores morales (SILVA, 2019, p. 384).

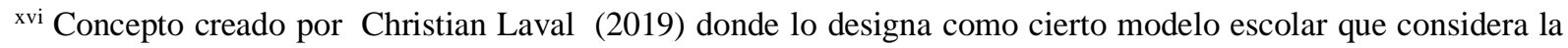
educación como un bien esencialmente privado, cuyo valor es ácima de todo económico.

xvii Libros que siguen los profesores de educación básica y media en São Paulo, de acuerdo al ministerio de educación nacional donde plantean todo el currículo en las escuelas.

xviii Según Deleuze (1987) signo es aquello que ejerce sobre la subjetividad una acción directa, sin la mediación de la representación. Lo que puede ser sentido y fuerza a la sensibilidad a elevarse a su maxima potencia. Los signos son emitidos por materias, objetos, personas, pero no son formas, objetos o sujetos. Los signos son un tipo de cualidad, de esencia o diferencia que existe en medio de cualquier materia y no sólo en la materia linguística. Ofrece un sentido, en cuanto a la forma de ser ejercida.

xix “Desde mi ventana ( $1^{\circ}$ de diciembre de 1976), veo a una mujer llevando a su hijo de la mano y empujando un cochecito vacío delante de ella. Iba imperturbable, a su paso, el chico estaba tironeando, sacudido, obligado a correr todo el tiempo, como un animal o una victima sadiana a la que castigan. Ella va a su ritmo, sin saber que el ritmo del chico es otro. Y sin embargo, jes su madre! $\rightarrow$ el poder-la sutileza del poder-pasa por la disritmia, la heterorritmia" (BARTHES, 2013, p.52).

${ }^{\mathrm{xx}}$ Disciplina “Arte, Estética e Política” Ministrada por Eugénia Vilela, UPORTO, Porto, 05/12/2017.

${ }^{\mathrm{xxi}}$ Hay territorio a partir del momento en que componentes del medio pasan a ser direccionales para volverse dimensionales, cuando paran de ser funcional para tornarse expresivos. Hay territorio a partir del momento en que hay una expresividad del ritmo (DELEUZE; GUATTARI 1997, p. 14). 